\title{
Os benefícios do coprocessamento de pneus inserviveis para a indústria cimenteira
}

\author{
The benefits of co-processing wasted tires for the cement industry
}

Sidcléa Sousa Freitas', Cláudia Coutinho Nóbrega²

口-

\section{RESUMO}

O pneu inservível é um resíduo que deve ser gerido corretamente até sua disposição final, pois quando disposto inadequadamente pode causar danos ao meio ambiente e à saúde pública. Em João Pessoa, Paraíba, foi iniciado em março de 2005 o Programa Nordeste Rodando Limpo, que consistiu na coleta e destinação final dos pneus inservíveis para utilização como combustível em fornos de fabricação de clínquer. Esta pesquisa foi desenvolvida em uma cimenteira, localizada na cidade de João Pessoa, cujo objetivo foi analisar os principais benefícios da utilização de pneus inservíveis no coprocessamento. A metodologia utilizada foi baseada na avaliação qualitativa dos benefícios gerados à saúde pública e avaliação quantitativa dos ganhos sociais gerados aos catadores, assim como mensurar as emissões atmosféricas do coprocessamento. Os resultados obtidos confirmaram os benefícios no coprocessamento, possibilitando a retirada de 26.569 toneladas de pneus inservíveis que estavam depositados nos estados da Paraíba, Pernambuco e Rio Grande do Norte, além da criação de um mecanismo de coleta pela sociedade, que possibilitou ganhos econômicos da ordem de $\mathrm{R} \$ 2$ milhões aos catadores, contribuindo para a melhoria de sua qualidade de vida. Verificou-se também um gradativo aumento da utilização de pneus inservíveis, implicando em um menor consumo de combustíveis não renováveis, minimizando emissões atmosféricas, devido ao menor volume de coque utilizado e transportado. Palavras-chave: cimento; coprocessamento; emissões atmosféricas; pneus inservíveis; resíduos; reutilização.

\begin{abstract}
The wasted tire is a residue that must be properly managed until its final disposal, because when improperly disposed, it can cause damage to the environment and risk to public health. In the city of João Pessoa, Paraíba, Brazil, a program called Programa Nordeste Rodando Limpo was started in March 2005 and consisted of the collecting and disposal of scrap tires to be used as fuel in furnaces for manufacturing of clinker. This research was conducted in a cement factory located in the city of João Pessoa. The main objective was to analyze the benefits of using scrap tires in co-processing. The methodology used was based on qualitative assessment of the benefits generated to the public health; quantitative assessment of the social gains generated to collectors; as well as the measurement of atmospheric emissions during the co-processing. The results confirmed the benefits in co-processing, allowing the removal of 26.569 tons of waste tires that were deposited in the states of Paraiba, Pernambuco and Rio Grande do Norte. A social mechanism for collecting waste tires was created, which enabled economic gains of R $\$ 2$ million to collectors, helping to improve their quality of life. There was also a gradual increase in the use of wasted tires, resulting in a lower consumption of non-renewable fuels, minimizing atmospheric emissions due to the lower volume of petroleum coke used and transported.
\end{abstract}

Keywords: cement; co-processing; atmospheric emissions; useless tires; waste; reutilization.

\section{INTRODUÇÃO}

Quando não tratados de forma adequada, os pneus inservíveis se tornam um perigoso passivo ambiental, provocando sérios danos de ordem ambiental, social e de saúde pública. A produção brasileira de pneus foi iniciada em 1934, quando foi implantado o Plano Geral de Viação Nacional. Segundo o Compromisso Empresarial para a Reciclagem (CEMPRE), os pneus e câmaras de ar consumiam cerca de $70 \%$ da produção nacional de borracha no ano de 1999 (CEMPRE, 2000). No ano de 2007, a indústria brasileira de pneus produziu um total de 61,3 milhões de unidades, avaliadas em R 9 bilhões, segundo dados do Instituto Brasileiro de Geografia e Estatística (IBGE, 2007). Sendo que, desse total, 53,8 milhões de unidades foram produzidas pelas 8 empresas associadas à Associação Nacional da Indústria de Pneumáticos (ANIP), representando assim o montante de $87 \%$ da produção total brasileira (ANIP, 2010). $\square$

'Pós-graduanda em Engenharia Urbana e Ambiental da Universidade Federal da Paraíba (UFPB) - João Pessoa (PB), Brasil.

2Professora Doutora do Departamento de Engenharia Civil e Ambiental e Coordenadora do Curso de Engenharia Ambiental da UFPB - João Pessoa (PB), Brasil. Endereço para correspondência: Sidcléa Sousa Freitas - Rua Caetano de Figueiredo, 1417 - 58071-220 - João Pessoa (PB), Brasil - E-mail: sidcleas@cimpor.com Fonte de financiamento: Universidade Federal da Paraíba (UFPB).

Recebido: 27/12/12 - Aceito: 28/01/14 - Reg. ABES: 769 
Um dos grandes problemas em relação aos pneus inservíveis é o gradativo aumento de sua produção em face ao aumento de produção de veículos automotores em nosso país. A indústria de cimento japonesa produziu 82 milhões de toneladas de cimento no ano 2000 e utilizou 27 milhões de toneladas de resíduos e subprodutos na substituição de matérias-primas e combustíveis. A indústria de cimento recebe várias centenas de tipos de matérias-primas alternativas, e denominam Ecocement o cimento produzido com a utilização de resíduos, este vem sendo elogiado pelo papel que vem desempenhando na preservação do meio ambiente no século XXI (HIROSE, 2004).

Antes de se tornarem inservíveis, os pneus usados podem ser reformados para que sua vida útil como equipamento automotivo seja prolongado por mais alguns anos. No Brasil, a prática é permitida, desde que seja realizada com componentes que foram utilizados em território nacional e podem ser de três tipos: recapagem, recauchutagem e remoldagem (CONAMA, 1999a).

Segundo Sandroni e Pacheco (2005), as alternativas mais utilizadas para a destinação dos pneus inservíveis no Brasil são classificadas como: recauchutagem, regeneração, reciclagem energética, pirólise e composição asfáltica, além de diversas formas de reutilização. Segundo Chen et al. (2009), os pneus inservíveis não são tratados como perigosos, porém, caso ocorra um incêndio, a fumaça resultante contém poluentes nocivos à saúde humana, podendo afetar o bem-estar físico e psicológico das pessoas.

A Resolução do Conselho Nacional de Meio Ambiente (CONAMA) $n^{\circ}$ 258/99 (CONAMA, 1999a) determina responsabilidades, prazos e quantidades para a coleta, reciclagem e destino final para os pneus inservíveis existentes no território nacional. Essa legislação impôs, a partir de 2002, a obrigatoriedade de destinar corretamente um pneu inservível para cada quatro novos produzidos, importados e reformados. A cada ano, a obrigatoriedade foi crescendo até chegar a 5 pneus para cada 4 pneus produzidos a partir de 2005. No ano de 2009, a publicação da Resolução no 416/2009 do CONAMA (CONAMA, 2009) revogou as Resoluções n 258, de 26 de agosto de 1999 (CONAMA, 1999a), e n 301, de 21 de março de 2002 (CONAMA, 2002), que dispõem sobre a prevenção à degradação ambiental causada por pneus inservíveis e sua destinação ambientalmente adequada. Caracteriza a destinação ambientalmente adequada de pneus inservíveis: procedimentos técnicos em que os pneus são descaracterizados de forma inicial e em que seus elementos constituintes são reaproveitados, reciclados ou processados por outra técnica admitida pelos órgãos ambientais competentes, de modo a evitar danos ou riscos à saúde pública e à segurança, e a minimizar os impactos ambientais adversos. Prevê também que os fabricantes e os importadores de pneus novos deverão implantar, nos municípios acima de 100 mil habitantes, pelo menos um ponto de coleta. A resolução supracitada determina que para cada pneu novo comercializado para o mercado de reposição, as empresas fabricantes ou importadoras deverão dar destinação adequada a um pneu inservível.

Visando tentar atender à legislação, foi implantado em 1999 o Programa Nacional de Coleta e Destinação de Pneus Inservíveis em todo o território nacional. Em 2007, o mesmo foi aperfeiçoado e passou a ser realizado através da RECICLANIP, que é uma entidade voltada exclusivamente para a coleta e destinação de pneus no Brasil. Através de parcerias com distribuidores, revendedores e prefeituras foi possível a implantação de centros de recepção de pneus inservíveis, os chamados Ecopontos (ANIP, 2010). Ainda segundo a ANIP (2010), no Brasil há 457 pontos para coleta de pneus inservíveis, porém, quando o número é comparado aos 5.564 municípios existentes no país, torna-se desprezível.

O pneu inservível é atrativo para utilização como combustível alternativo ao coque de petróleo e carvão mineral na indústria cimenteira devido ao seu elevado poder calorífico (MARQUES, 1999). A recuperação de energia contida nos resíduos contribui adicionalmente para a conservação de combustíveis fósseis não renováveis, reduzindo os custos de fabricação, pois os combustíveis provenientes de resíduos energéticos são mais baratos do que qualquer combustível fóssil tradicional, o que incentiva esse potencial de energia. A grande vantagem da utilização de pneus em fornos de cimento é sua total destruição, em função das elevadas temperaturas, e retenção de cinzas na matriz do clínquer, pois todo o processo ocorre num sistema fechado, não gerando fumaça ou pó (MARQUES, 1999). Dessa forma, Tarckiani (2003), menciona que a cimenteira inglesa Blue Circle Cauldon, ao substituir 15\% do carvão para produção de clínquer por pneu, obteve uma diminuição de $4 \%$ nas emissões de dióxido de enxofre, $32 \%$ de óxido de nitrogênio e $75 \%$ de dioxinas.

Por isso, a solução de destinação de resíduos através do coprocessamento vem sendo adotada por países desenvolvidos desde a década de 1970 e, desde então, vem sendo difundida e utilizada em todo o mundo. De acordo com Cavalcanti (1996), as atividades de coprocessamento de resíduos na indústria cimenteira no Brasil foram iniciadas na década de 1990, no estado de São Paulo.

Porém, para que o coprocessamento possa ser realizado, o resíduo deve estar disponível nas unidades de fabricação de cimento. A coleta é um dos principais problemas para a destinação final dos pneus inservíveis, pois não existe um processo de coleta diferenciado e eficaz, uma vez que, normalmente, esses elementos não estão inseridos como item na gestão de resíduos sólidos. Porém, algumas ações vêm sendo realizadas nesse sentido, conseguindo aliar benefícios ao meio ambiente, saúde pública e sociedade. Uma delas é o Programa Nordeste Rodando Limpo, que consiste na coleta dos pneus inservíveis do meio ambiente pelos catadores, que muitas vezes encontram alternativa de emprego e renda na informalidade, pois fazem parte de um grupo que, devido à condição social 
e baixa escolaridade, tem dificuldade de inserção no mercado de trabalho formal. Os benefícios dos programas de coleta de resíduos são verificados nas diferentes etapas da reciclagem. De acordo com Ramos Filho (2005), no ano de 2004, ao ser iniciada a coleta de pneus inservíveis na cidade de Curitiba, no estado do Paraná (região sul do Brasil), a mobilização dos catadores para a coleta de resíduos sólidos, organizados na forma de cooperativas, ocasionou um aumento na média de renda dessas pessoas em até dois salários mínimos, gerando-se também, postos de trabalho permanentes.

Por sua vez, os catadores são remunerados pelas indústrias cimenteiras, gerando, assim, um incremento na renda e uma consequente melhoria em sua qualidade de vida. Desta forma, foram avaliados os benefícios sociais, ambientais e econômicos do coprocessamento de pneus inservíveis em uma indústria brasileira localizada no município de João Pessoa, Paraíba, no período de março de 2005 a dezembro de 2009.

De acordo com o Sindicato nacional da Indústria do Cimento (SNIC), existem 65 fábricas de cimento instaladas no Brasil, sendo que 35 estão licenciadas pelos órgãos ambientais para coprocessar resíduos, possuindo uma capacidade potencial de destruição de 2,5 milhões de toneladas de resíduos com composições diversas. A utilização desses resíduos como combustível alternativo representou uma substituição de 15\% de combustíveis fósseis não renováveis em 2007 (SNIC, 2008).

A técnica do coprocessamento é o processo de oxidação térmica de resíduos nos fornos de fabricação de clínquer, principal composto na fabricação do cimento. A atividade é realizada no interior de um forno que possui em média $60 \mathrm{~m}$ de comprimento e $4 \mathrm{~m}$ de diâmetro, alcançando temperaturas da ordem de $1.400^{\circ} \mathrm{C}$ na zona de clinquerização e um tempo de residência para os gases de até 10 segundos. De acordo com Marques (1999), essas condições resultam na destruição de quase toda carga orgânica, e as cinzas são formadas por componentes inorgânicos, ficando incorporadas ao clínquer.

Os poluentes primários emitidos na fabricação de cimento são: material particulado, óxidos de nitrogênio, dióxido de enxofre, monóxido de carbono e dióxido de carbono. Alguns outros componentes em menores quantidades são considerados poluentes atmosféricos perigosos, como compostos orgânicos voláteis, amônia, cloro, cloreto de hidrogênio e produtos da combustão incompleta. A Resolução do CONAMA No 264/99 (CONAMA, 1999b) estabelece limites de emissões atmosféricas para as instalações de fornos de clínquer de acordo com testes realizados com o acompanhamento do órgão ambiental competente nas plantas de fabricação de cimento.

\section{METODOLOGIA}

Como citado anteriormente, este trabalho foi desenvolvido em uma fábrica de cimento localizada na cidade de João Pessoa, no estado da Paraíba, onde se procurou evidenciar a técnica de utilização dos pneus inservíveis no forno de clínquer, assim como o tipo de operação para a alimentação de pneus inservíveis e controle.

Buscando mensurar os dados referentes à coleta dos pneus inservíveis, dados relevantes como quantidade de pneus coletados e valor pago aos catadores foram obtidos com a cimenteira, no Programa Nordeste Rodando Limpo, desenvolvido em parceria com a empresa BSColway.

Com o intuito de avaliar o perfil social dos catadores e os benefícios alcançados com a atividade de coleta de pneus inservíveis, foi aplicado um questionário numa amostra de 21 catadores que realizaram a entrega na referida cimenteira no período de 9 a 20 de novembro de 2009. De posse dos resultados, foi realizada análise de interpretação e traçado o perfil socioeconômico dos mesmos, incluindo os benefícios que a atividade lhes proporcionou e informações ambientais da coleta dos pneus inservíveis.

Para verificar os benefícios diretos à saúde pública, foi realizada uma entrevista aberta ao coordenador da gerência operacional de vigilância sanitária da Secretaria de Saúde do Estado da Paraíba, visando analisar as ações adotadas na cidade de João Pessoa referentes à coleta e destinação de pneus.

Por fim, foi realizado um comparativo das características dos combustíveis convencionais utilizados no forno de clínquer versus os pneus inservíveis, através de análises físicas e químicas coletadas junto à cimenteira, possibilitando verificar a viabilidade econômica da utilização dos pneus, mensurando os ganhos econômicos gerados. Para a verificação das emissões geradas foram seguidas as metodologias NBR 12019 e NBR 12022 da Associação Brasileira de Normas Técnicas (ABNT) para determinação de material particulado e dióxido de enxofre; a L9.229 da Companhia de Tecnologia de Saneamento Ambiental (CETESB) para determinação de óxidos de nitrogênio; e o Method 23 US EPA da United States Environmental Protection Agency para determinação de dioxinas e furanos.

\section{RESULTADOS E DISCUSSÃO}

\section{Perfil social dos catadores}

Após aplicação de questionário específico, com o intuito de verificar o perfil social dos catadores de pneus, chegou-se aos seguintes resultados: $52 \%$ dos catadores tinham faixa etária entre 41 e 50 anos e $43 \%$ possuíam o ensino fundamental incompleto. Dos entrevistados, $43 \%$ eram provenientes do município de João Pessoa, e 24\% de Bayeux, que são os mais próximos ao ponto de entrega dos pneus. Para 33\% dos entrevistados a atividade de coleta de pneus era a principal fonte de renda, os outros $67 \%$ desempenhavam outras atividades, sendo que a maioria trabalhava com "fretes". Verificou-se que a remuneração média encontrada em 52\% dos entrevistados situava-se entre 1 e 3 salários mínimos, e 24\% declararam ter remuneração mensal menor que 1 salário mínimo. Quando perguntado quantos pneus eram entregues mensalmente, a 
maioria (67\%) respondeu que mais de 200 pneus. Quanto à entrega, 95\% dos catadores a realizavam através de veículo motorizado e apenas 5\% utilizavam de carroça de mão.

Outra constatação foi que $62 \%$ dos pneus eram coletados diretamente em borracharias, $24 \%$ em empresas e apenas $14 \%$ diretamente da rua, demonstrando que ao valorizar o pneu inservível, foi estabelecido um mecanismo de coleta por meio da sociedade, retirando-o das ruas e minimizando os possíveis impactos que o seu acondicionamento inadequado poderia acarretar.

\section{Benefícios sociais}

A inserção dos pneus inservíveis como item de coleta para os catadores de resíduos significou um ganho importantíssimo no que diz respeito ao aumento da sua renda mensal, uma vez que a receita de $\mathrm{R} \$ 2.097 .712$ (US\$1.031.120,72) foi repassada aos catadores no período de março de 2005 a dezembro de 2009, ocasionando a retirada de 26.569 toneladas de pneus inservíveis de ruas, terrenos baldios, depósitos improvisados e residências do estado da Paraíba (Tabela 1). Com a inserção do pneu inservível como item de coleta para os catadores de resíduos, foi criado automaticamente um mecanismo de coleta, que passou a ser feita diretamente em empresas e residências.

Para cada tipo de pneu coletado era estipulado um valor para pagamento ao catador. Era pago o valor de $\mathrm{R} \$ 0,40$ para cada pneu de automóvel entregue, $\mathrm{R} \$ 0,80$ para cada pneu de caminhonete e $\mathrm{R} \$ 2,00$ para cada pneu de caminhão.

O Programa Nordeste Rodando Limpo foi criado e subsidiado pelo Instituto BSColway até o mês de dezembro de 2007, quando por decisão do Supremo Tribunal Federal (STF) foi proibida a importação dos pneus usados, essenciais para o processo de remoldagem de pneus. Desta forma, o Programa passou, no ano de 2008, a ser realizado exclusivamente pela cimenteira, que para dar continuidade ao programa necessitou diminuir o valor pago aos catadores pela metade, continuando dessa forma até o final do ano de 2009. Devido a esse fato, pode-se observar uma queda de $54,04 \%$ de pneus recebidos em

Tabela 1 - Quantidade de pneus coletados pelo Programa Nordeste Rodando Limpo.

\begin{tabular}{l|c|c|c} 
Ano & Quantidade de pneus (t) & Renda (R\$) & Renda (U\$)* \\
\hline 2005 & $3.093,03$ & $247.442,40$ & $121.629,17$ \\
\hline 2006 & $5.624,87$ & $449.989,60$ & $251.390,83$ \\
\hline 2007 & $5.416,00$ & $433.280,00$ & $247.642,45$ \\
\hline 2008 & $8.519,00$ & $681.000,00$ & $380.446,92$ \\
\hline 2009 & $3.916,00$ & $286.000,00$ & $159.776,53$ \\
\hline Total & $26.568,90$ & $2.097 .712,00$ & $1.031 .120,72$ \\
\hline
\end{tabular}

Fonte: CIMPOR (2010)

*Cotação do Dólar 2,0344 em 06/11/2012 (BACEN, 2010). relação ao mesmo período de 2008 (Tabela 1). No início de 2010, a RECICLANIP assumiu o controle do recebimento dos pneus, passando a não mais pagar pelos pneus aos catadores.

Percebe-se então, que para a continuidade da sistemática de coleta é necessário valorizar o pneu inservível, tornando o programa de coleta autossustentável, uma vez que esse resíduo é valorizado como combustível nos fornos de clínquer, pois de forma contrária a responsabilidade da coleta recairia mais uma vez para os órgãos públicos, tornando-se, acima de tudo, uma grave questão de saúde pública.

A coleta de pneus no município de João Pessoa, Paraíba, vem sendo realizada, desde 1997, com o objetivo de minimizar os criadouros do mosquito transmissor da dengue (PARAÍBA, 2010). Porém, sem opção para a correta destinação final, os pneus eram queimados a céu aberto, no bairro de Mangabeira. Com o início do coprocessamento, todos os bairros de João Pessoa foram beneficiados, porém, o bairro que mais necessitava de uma coleta periódica era o do Varadouro, por possuir um grande número de oficinas automotivas e "sucatas metálicas", gerando um grande número de pneus inservíveis. Em termos quantitativos, não foi possível mensurar valores economizados pela Secretaria de Saúde do Estado da Paraíba (SESPB) no combate à dengue no município de João Pessoa, pois não existe estudo direcionado. Porém, empiricamente pode-se afirmar que, a partir da redução do número de criadouros que o agente ambiental necessita inspecionar e aplicar o praguicida há uma redução significativa de custos e melhoria no trabalho.

Como o estado da Paraíba ainda não possui um ecoponto mantido pela RECICLANIP, a SESPB entende que não só o município de João Pessoa, mas também todos os demais municípios paraibanos necessitam estruturar seus locais para armazenamento dos pneus inservíveis.

A SESPB, através da Vigilância Ambiental, articulou uma parceria com os municípios paraibanos buscando uma reorganização no fluxo de coleta, armazenamento, transporte e destino final, sendo: a coleta e o armazenamento de responsabilidade dos municípios, transporte do local de armazenamento de responsabilidade do Governo do Estado e o destino final a cimenteira. Cabedelo, Bayeux, Santa Rita e Conde são os quatro municípios da área metropolitana de João Pessoa que recolhem e encaminham diretamente para a fábrica. Essa iniciativa da participação do Estado no transporte dos pneus é transitória, pois se entende que a legislação vigente, quanto ao recolhimento de pneus, deve ser cumprida pelos fabricantes. Desta forma, buscou-se a participação da RECICLANIP, entidade que foi referenciada como responsável pelo transporte até o destino final, porém as exigências solicitadas estão fora da realidade atual do Governo do Estado e demandam tempo para adequação.

\section{Benefícios ambientais}

Foi verificada uma economia de recursos não renováveis através da redução do consumo de coque de petróleo com a substituição dos pneus 
inservíveis. Como o Poder Calorífico Inferior (PCI) de ambos é conhecido, é possível relacionar os dois combustíveis (Tabela 2) da seguinte forma: 1,00 tonelada de pneus inservíveis equivale a 1,01 toneladas de coque de petróleo, ou seja, para se obter o mesmo PCI deve-se utilizar uma maior quantidade de coque de petróleo no formo de clínquer. No período de março de 2005 a dezembro de 2009 foram utilizadas 18.880,29 toneladas de pneus no forno de clínquer, representando uma redução de 18.874,06 toneladas de coque de petróleo.

Tabela 2 - Características dos combustíveis utilizados no forno de clínquer.

\begin{tabular}{l|c|c} 
Item & Coque & Pneu inservivel \\
\hline $\mathrm{PCl}\left(\mathrm{kcal}^{\mathrm{k}} \mathrm{kg}\right)$ & $8.192,41$ & $8.302,28$ \\
\hline Percentual de S (\%) & 6,46 & 1,72 \\
\hline Preço do produto (R\$/t) & 170,00 & 80,00 \\
\hline
\end{tabular}

PCl: poder calorifico inferior

Fonte: CIMPOR (2010).

Tabela 3 - Consumo de combustíveis não renováveis.

\begin{tabular}{l|c|c|c} 
Periodo & $\begin{array}{c}\text { Produção } \\
\text { de clinquer }\end{array}$ & Coque $(\mathrm{t})$ & $\begin{array}{c}\text { Pneus } \\
\text { inserviveis (t) }\end{array}$ \\
\hline 2005 (mar-dez) & $486.188,00$ & $51.952,25$ & 2044,07 \\
\hline 2006 & $540.705,00$ & $56.143,76$ & 3191,61 \\
\hline 2007 & $562.126,00$ & $63.653,50$ & 4894,75 \\
\hline 2008 & $523.607,00$ & $52.093,78$ & 4364,58 \\
\hline 2009 & $489.936,00$ & $49.333,89$ & 4385,53 \\
\hline
\end{tabular}

Fonte: CIMPOR (2010).

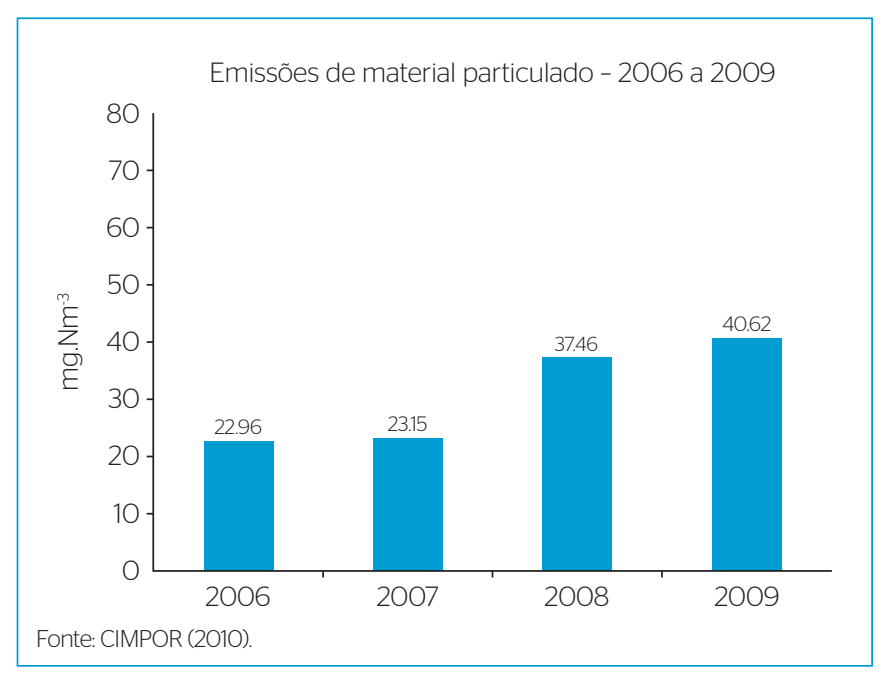

Figura 1 - Emissões atmosféricas de material particulado.
Quando comparado o consumo de combustíveis convencionais com o consumo de pneus inservíveis no período de março de 2005 a dezembro de 2009 (Tabela 3), pode-se perceber o aumento gradativo da utilização do pneu inservível, levando-se em conta também o aumento da produtividade do período citado anteriormente.

$\mathrm{Na}$ fábrica, foram monitorados de forma contínua os seguintes parâmetros: Material Particulado (MP), através de opacímetro, óxidos de enxofre $\left(\mathrm{SO}_{\mathrm{x}}\right)$, óxidos de nitrogênio $\left(\mathrm{NO}_{\mathrm{x}}\right)$, monóxido de carbono (CO), oxigênio $\left(\mathrm{O}_{2}\right)$ e hidrocarbonetos (THC), através de medidor de gases. Além de ser realizado o automonitoramento, eram enviados relatórios mensalmente à Superintendência de Desenvolvimento e Meio Ambiente (SUDEMA), órgão ambiental paraibano, com as concentrações dos parâmetros medidos continuamente. Anualmente é realizado por uma empresa externa um monitoramento das emissões dos parâmetros monitorando continuamente, além de metais pesados, dioxinas e furanos e outros. As Figuras 1 e 2 mostram as emissões de $\mathrm{MP}, \mathrm{SO}_{\mathrm{x}}$ e $\mathrm{NO}_{\mathrm{x}}$ no período de 2006 a 2009.

Os valores de medições anuais de material particulado no período de estudo com a utilização de resíduos no forno de clínquer da CIMPOR, incluindo os pneus inservíveis, indicaram que as emissões atmosféricas de material particulado estão dentro dos limites estabelecidos pela Resolução n 264/99 do CONAMA (CONAMA, 1999b), que preconiza $70 \mathrm{mg} . \mathrm{Nm}^{-3}$, porém, foi verificada no ano de 2009 a maior concentração de emissões, com valores na ordem de 40,62 mg. $\mathrm{Nm}^{-3}$. As possíveis causas para esse aumento são o aumento dos gases de exaustão do processo produtivo ou o desgaste dos materiais filtrantes presentes no filtro de mangas, fatores diretamente ligados à emissão de MP. O material particulado, por ser o grande agente poluidor da indústria cimenteira, é bem controlado através de sistemas de desempoeiramento, que são os filtros de mangas.

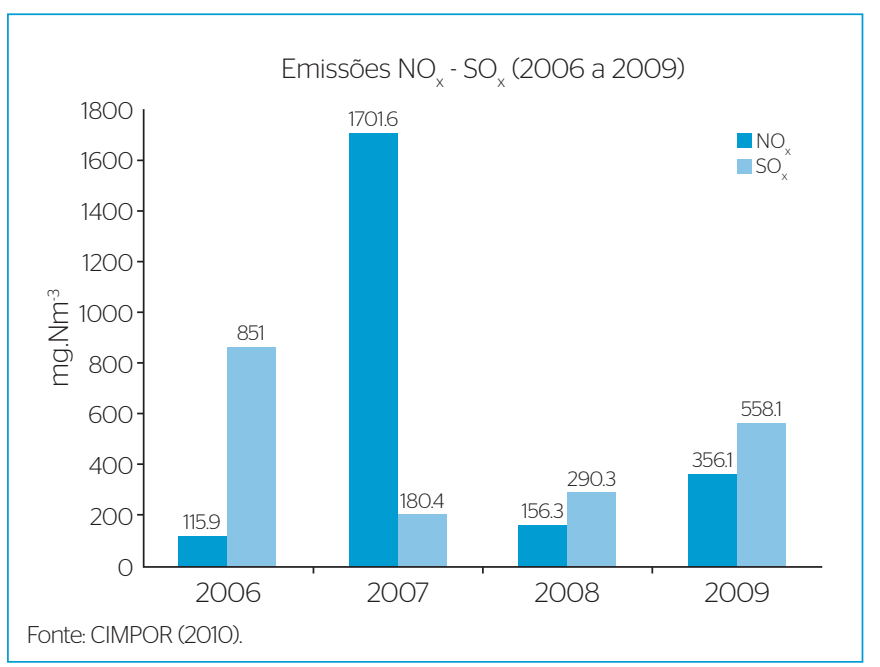

Figura 2 - Emissões atmosféricas de óxido de nitrogênio $\left(\mathrm{NO}_{x}\right)$ e óxido de enxofre $\left(\mathrm{SO}_{x}\right)$. 
Os parâmetros $\mathrm{NO}_{\mathrm{x}}$ e $\mathrm{SO}_{\mathrm{x}}$ não possuem valores limites estabelecidos na legislação federal, sendo de responsabilidades dos órgãos ambientais locais, que podem estabelecer parâmetros de controle, de acordo com as especificidades de cada local e de acordo com o teste de queima. Em São Paulo estão estabelecidos os limites de 350 mg. Nm ${ }^{-3}$ de SOx e 800 mg.Nm³ de NOx. Na Paraíba não há limites para estes poluentes. As Figuras 3, 4 e 5 mostram as emissões de metais, dioxinas e furanos, respectivamente, medidos nos períodos de 2006, 2008 e 2009. Verificou-se que as emissões de $\mathrm{NO}_{x}$ e $\mathrm{SO}_{\mathrm{x}}$, quando comparadas com os limites de referência para o Estado de São Paulo, excederam em $47 \%$ no ano de 2007 para o $\mathrm{NO}_{\mathrm{x}}$ e em $41 \%$ no ano de 2006 e $62 \%$ para o ano de 2009 para o $\mathrm{SO}_{\mathrm{x}}$.

As emissões atmosféricas apresentadas são resultantes do processo de combustão de diversos combustíveis, dentre eles o pneu inservível.

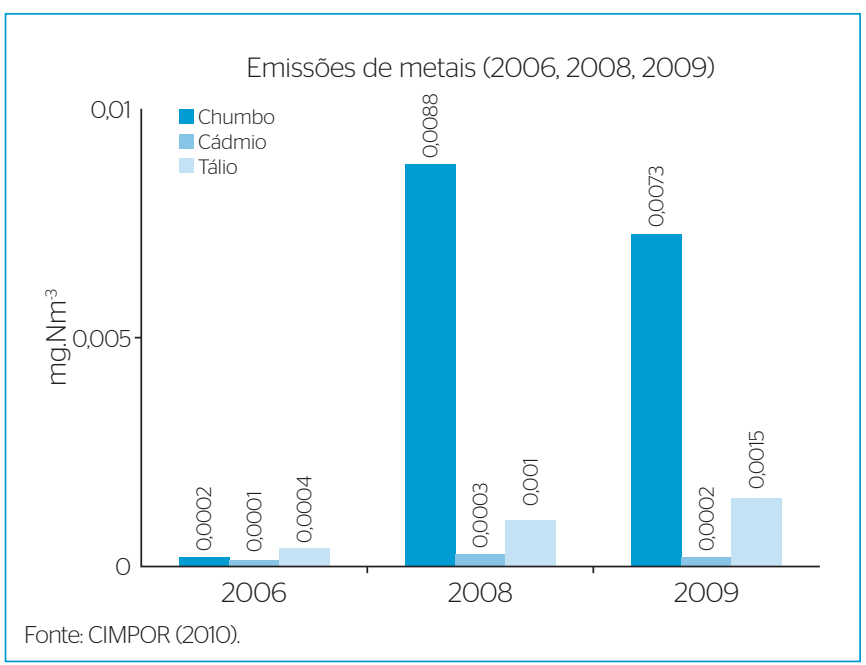

Figura 3 - Emissões atmosféricas de metais.

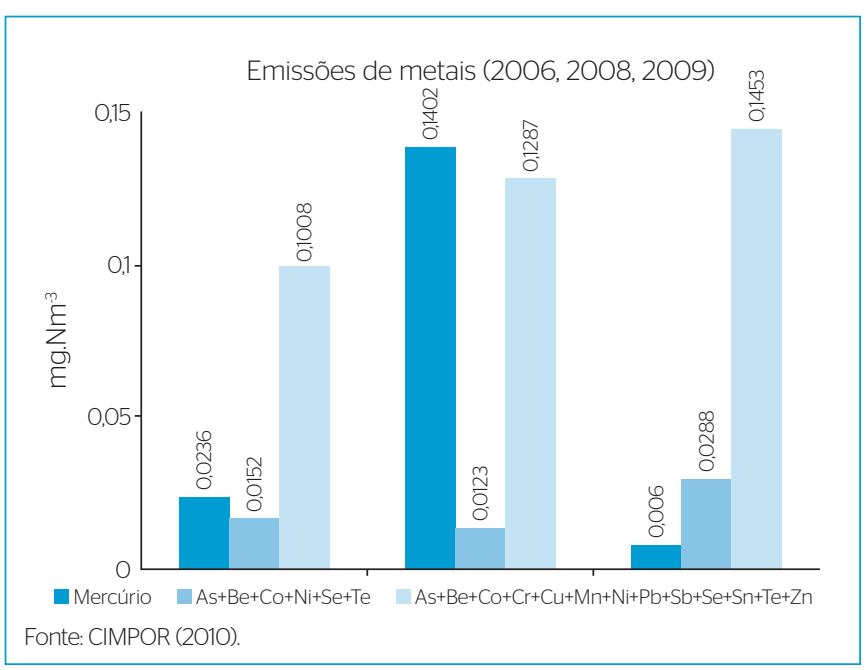

Figura 4 - Emissões atmosféricas de metais por tipo.
A formação de compostos de nitrogênio $\left(\mathrm{NO}_{\mathrm{x}}\right)$ está associada ao processo de combustão e às características do combustíveis utilizados.

É no processo de volatilização do enxofre presente nas matérias-primas que as emissões de $\mathrm{SO}_{2}$ têm a sua principal origem, sendo menor sua contribuição nos combustíveis. Deste modo, como primeira medida de mitigação das emissões de $\mathrm{SO}_{2}$ deve-se ter controle e gestão da exploração das matérias-primas utilizadas, assim como na escolha de combustíveis com menores teores de enxofre. A redução das emissões de $\mathrm{SO}_{2}$ foi verificada através da concentração de enxofre presente nos dois combustíveis. De acordo com a Tabela 2, observa-se na composição do coque de petróleo 6,46\% de enxofre, enquanto que o pneu inservível apresenta apenas $1,72 \%$ em sua composição. Dessa forma foi possível determinar, então, uma queda de $26,62 \%$ de enxofre nas emissões de $\mathrm{SO}_{2}$, pois praticamente todo enxofre existente no combustível se oxida para $\mathrm{SO}_{2}$.

A presença de metais nas emissões tem origem nas matérias-primas e combustíveis utilizados no processo. O teor de metais no processo é bastante variável, embora sempre com níveis muito baixos. Vale ressaltar que a Resolução n 264/1999 do CONAMA (CONAMA, 1999b) considera limites para emissão de metais agrupados, não sendo considerados em separado, exceto o chumbo, o mercúrio, o cádmio e o tálio. O seu comportamento no forno depende fundamentalmente da volatilidade. Por esta razão, o mercúrio, metal extremamente volátil, surge como o elemento que mais se reflete em termos de emissões gasosas. $\mathrm{O}$ valor limite de emissão desse composto encontra-se estabelecido nos fornos que utilizam resíduos. Durante o período de estudo, esse valor foi de $0,05 \mathrm{mg} \cdot \mathrm{Nm}^{-3} \mathrm{e}$ a média das medições não contínuas realizadas no ano de 2009 foi de $0,006 \mathrm{mg}^{-\mathrm{Nm}^{-3}}$. Outro metal encontrado nas medições atmosféricas foi o chumbo, que se mostrou mais evidente nos anos de 2008 e 2009. A exposição ao chumbo pode provocar desvios no desenvolvimento neurológico e comportamental, causar danos hematológicos e hipertensão (SIQUEIRA, 2005).

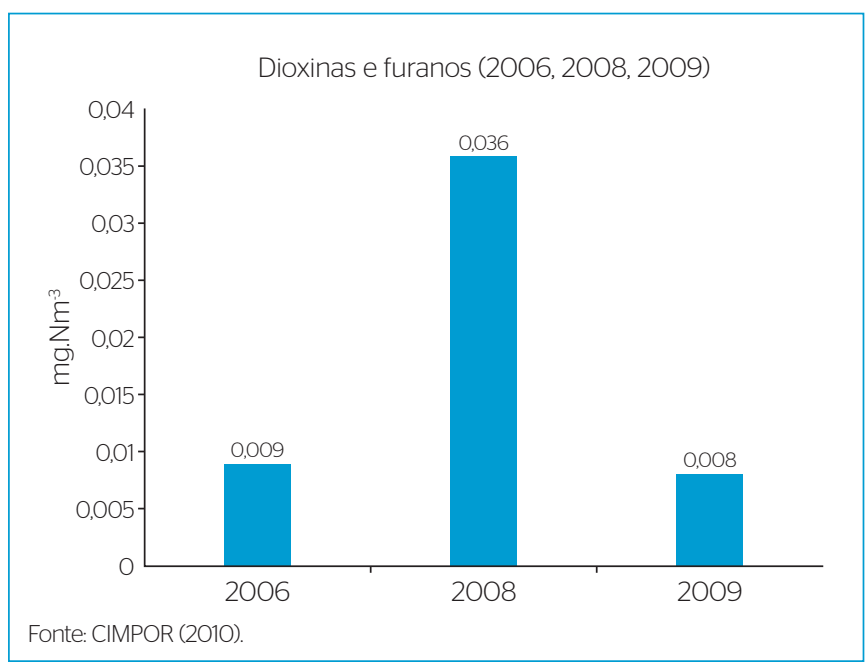

Figura 5 - Emissões atmosféricas de dioxinas e furanos. 
As dioxinas e furanos fazem parte de um grupo de poluentes denominados Poluentes Orgânicos Persistentes (POPs), cujos efeitos adversos se encontram associados à sua toxicidade, com consequente impacto ambiental e na saúde pública. Na indústria cimenteira, a emissão desses compostos é bastante reduzida. As medições pontuais efetuadas na cimenteira, periodicamente, nas chaminés dos fornos demonstram que as emissões de dioxinas e furanos encontram-se abaixo do valor limite 0,5 ng. $\mathrm{Nm}^{-3}$, sendo que o maior valor encontrado foi de $0,036 \mathrm{ng} \cdot \mathrm{Nm}^{-3}$.

Com o crescimento da atividade de coprocessamento, foi realizada a instalação de novos sistemas de controle de poluentes, visando a minimização das emissões atmosféricas geradas. Desta forma, a substituição de precipitadores eletrostáticos por filtros de mangas nos sistemas de resfriamento de clínquer no ano de 2008 e da moagem de cru no ano de 2009, possibilitaram uma maior eficiência no controle das emissões de material particulado na cimenteira estudada.

\section{Benefícios econômicos}

De posse dos percentuais de substituição dos combustíveis alternativos pelo coque de petróleo no período de 2006 a 2009, foram calculados os valores anuais economizados com a utilização dos pneus inservíveis. Para realização dos cálculos foi convertido o valor R $\$$ /unidade para $\mathrm{R} \$ / \mathrm{t}$, que equivale a R\$ 80,00/t (Tabela 2). Para o cálculo da economia anual foi considerado o funcionamento anual do forno de clínquer de 300 dias, devido às paradas desse equipamento para produção e manutenção, além da média histórica de $830 \mathrm{kcal} \cdot \mathrm{kg}^{-1}$ de clínquer relativo ao consumo em calor forno.

A Tabela 4 mostra os valores de substituição térmica dos pneus, calculados em reais economizados com a utilização dos pneus como fonte de calor no forno de clínquer.

Comparando os valores economizados com a utilização dos pneus em substituição ao coque em termos de economia anual, verificou-se que o ganho econômico foi bastante representativo, pois no cálculo dos valores correspondentes à economia anual está descontado o valor pago aos catadores pela compra dos pneus.

\section{CONCLUSÕES}

A questão dos pneus inservíveis é um problema que está inserido diretamente na sociedade, podendo trazer graves consequências ambientais e de saúde pública. Uma das formas de solucionar esse problema é a efetiva fiscalização do poder público junto às empresas fabricantes de pneus. Como visto neste trabalho, o coprocessamento de resíduos em fornos de clínquer possibilita uma ótima solução para a utilização dos pneus inservíveis como alternativa na substituição de combustíveis fósseis, seja pelo seu elevado poder calorífico, ou devido ao baixo teor de enxofre, minimizando as emissões de $\mathrm{SO}_{2}$. Devido à coleta ser uma das fases mais complexas para a destinação final dos pneus, deve-se garantir que essa etapa seja realizada de forma correta, por isso é inevitável que

Tabela 4 - Características da economia de coque de petróleo com a utilização de pneus inservíveis.

\begin{tabular}{|c|c|c|c|c|c|c|}
\hline Dados & Coque & Pneu & \multicolumn{2}{|c|}{$\begin{array}{l}\text { Produção do forno } \\
\text { (kg.dia') }\end{array}$} & \multicolumn{2}{|c|}{$\begin{array}{l}\text { Consumo em calor } \\
\text { (kcal.kg }{ }^{-1} \text { clinquer) }\end{array}$} \\
\hline $\mathrm{PCl}$ & $8.192,41$ & $8.302,28$ & & & & \\
\hline S (\%) & 6,46 & 1,72 & \multicolumn{2}{|c|}{$2.200 .000,00$} & \multicolumn{2}{|c|}{830,00} \\
\hline Preço $(R \$ / t)$ & 170,00 & 80,00 & & & & \\
\hline Item & & & 2006 & 2007 & 2008 & 2009 \\
\hline Substituição em calor (\%) & & & 4,24 & 6,01 & 5,83 & 8,01 \\
\hline Consumo total de calor (kcal.dia') & & & 1.826 .000 .000 & 1.826.000.000 & 1.826.000.000 & 1.826.000.000 \\
\hline Calor proveniente dos pneus (kcal.dia') & & & 77.422 .400 & 109.742 .600 & 106.455 .800 & 146.262 .600 \\
\hline Massa diária de pneus coprocessada (kg.dia') & & & $9.325,44$ & $13.218,37$ & $12.822,48$ & $17.617,16$ \\
\hline Custo dos pneus $(\mathrm{R} \$$ ) & & & 746,04 & $1.057,47$ & $1.025,80$ & $1.409,37$ \\
\hline Custos dos pneus (U\$) & & & $1.144,80$ & $1.622,69$ & $1.574,09$ & $2.162,68$ \\
\hline Massa de coque equivalente à massa de pneus (kg) & & & $9.450,50$ & $13.395,64$ & $12.994,44$ & $17.853,43$ \\
\hline Custo do coque equivalente aos pneus ( $R \$$. dia') & & & $1.606,59$ & $2.277,26$ & $2.209,06$ & $3.035,08$ \\
\hline Economia mensal (R\$. mês') & & & $25.816,52$ & $36.593,69$ & $35.497,71$ & $48.771,30$ \\
\hline Economia anual ( $R \$$. ano-1) & & & $258.165,16$ & $365.936,94$ & $354.977,10$ & $487.712,96$ \\
\hline
\end{tabular}

Fonte: CIMPOR (2010)

PCl: poder calorífico inferior 
os fabricantes de pneus desenvolvam ações em conjunto com empresas privadas e o poder público. O programa Nordeste Rodando Limpo, além de gerar renda aos catadores de resíduos, possibilitou a retirada de 26.569 toneladas de pneus inservíveis que estavam depositados no estado da Paraíba e também em alguns estados vizinhos. Pode-se vislumbrar que, ao ser inserir o pneu inservível na coleta de resíduos, é criado automaticamente um mecanismo de coleta pela sociedade, retirando os mesmos das ruas e possibilitando ganhos econômicos aos catadores, melhorando sua qualidade de vida. Portanto, este trabalho mostrou que ações realizadas pelo setor de pneus em conjunto com a indústria cimenteira podem ajudar a resolver os graves problemas ambientais resultantes do descarte de pneus inservíveis.

\section{REFERÊNCIAS}

ABNT - ASSOCIAÇAO BRASILEIRA DE NORMAS TÉNICAS. (1990) NBR 12019: Efluentes gasosos em dutos e chaminés de fontes estacionárias - Determinação de material particulado - Método de ensaio. Rio de Janeiro.

ABNT - ASSOCIAÇAO BRASILEIRA DE NORMAS TÉNICAS. (1990) NBR 12022: Efluentes gasosos em dutos e chaminés de fontes estacionárias Determinação de dióxido de enxofre - Método de ensaio. Rio de Janeiro.

ANIP - ASSOCIAÇÃO NACIONAL DA INDÚSTRIA PNEUMATICA. (2010) Dados de Produção. Disponível em: <http://www.anip.com.br/index.ph p?cont=conteudo\&area=32\&titulo_pagina=Produção>. Acesso em: 18 fevereiro 2010

BACEN - BANCO CENTRAL DO BRASIL. (2012) Cotação do dólar em 06 de novembro de 2012. Disponível em: <http://www4.bcb.gov.br/pec/ taxas/batch/taxas.asp?id=txdolar>. Acesso em 06 novembro 2012.

CONAMA - CONSELHO NACIONAL DE MEIO AMBIENTE. (1999a) Resolução CONAMA no 258/99, de 20 de agosto de 1999. Resoluções, 1999. Disponível em: <http://www.mma.gov.br/port/conama/>. Acessado em: 14 março 2010.

CONAMA - CONSELHO NACIONAL DE MEIO AMBIENTE. (1999b) Resolução CONAMA no 264/99, de 26 de agosto de 1999. Resoluções, 1999. Disponível em: <http://www.mma.gov.br/port/conama/>. Acesso em 14 março 2010.

CONAMA - CONSELHO NACIONAL DE MEIO AMBIENTE. (2002) Resolução CONAMA no 301/O2, de 21 de março de 2002. Resoluções, 2002. Disponível em: <http://www.mma.gov.br/port/conama/>. Acesso em 14 março 2010.

CONAMA - CONSELHO NACIONAL DE MEIO AMBIENTE. (2009) Resolução CONAMA no 416/09, de 30 de setembro de 2009. Resoluções, 2009. Disponível em: <http://www.mma.gov.br/port/ conama/>. Acesso em 14 março 2010.

CAVALCANTI, J.E.W.A. (1996) Situação da Indústria de Co-processamento no Brasil. Saneamento Ambiental, n. 39, p. 22-23.

CEMPRE - COMPROMISSO EMPRESARIAL PARA RECICLAGEM. (2000) Pneus. Ficha Técnica 8, 2000. Disponível em: <http://www. cempre.org.br/fichas/ficha8.html> Acesso em 15 junho 2010.

CETESB - COMPANHIA DE TECNOLOGIA DE SANEAMENTO AMBIENTAL. (1992) L9. 229 - Determinação de óxidos de nitrogênio em efluentes gasosos de dutos e/ou chaminés de fontes estacionárias. São Paulo.
CHEN, C.C.; YAMADA, T.; CHIU, M.; LIU, Y. (2009) Evaluation of the waste tire resources recovery program and environmental health policy in Taiwan. International Journal of Environmental Research and Public Health, v.6, n. 3, p. 1075-1094.

CIMPOR - CIMENTOS DO BRASIL. (2010) Departamento de Produção Dados de Produção 2010.

EPA - US ENVIRONMENTAL PROTECTION AGENCY. Method 23 Determination of Polychlorinated Dibenzo-p-dioxins and Polychlorinated Dibenzofurans from Municipal Waste Combustors. USA.

HIROSE, S. (2004) Waste management technologies in Japanese cement industry - from manufacturing to ecofactuaring. Journal of Water and Environment Technology, v. 2, n. 1.

IBGE - INSTITUTO BRASILEIRO DE GEOGRAFIA E ESTATÍSTICA. (2007) Contagem da População 2007. Disponível em: <http://www.ibge.gov.br/ home/estatistica/populacao/contagem2007/default.shtm>. Acesso em 20 junho 2010.

MARQUES, M. (1999) Coprocessamento em fornos de cimento. Revista Gerenciamento Ambiental, n. 6 .

NASCIMENTO, N.G. (2010) Secretaria de Saúde do Estado da Paraíba.

RAMOS FILHO, L.S.N. (2005) A logística reversa de pneus inservíveis: o problema da localização dos pontos de coleta. Dissertação (Mestrado em Engenharia de Produção) - Universidade Federal de Santa Catarina, Florianópolis.

SANDRONI, M. \& PACHECO, E.B.A.V. (2005) O destino dos pneus inservíveis. Disponível em: <http://www.jorplast.com.br/jpoutO3/pag08. html>. Acesso em: 29 maio. 2010.

SIQUEIRA, L.C.G. (2005) Avaliação do impacto das emissões de metais geradas no coprocessamento de resíduos em fábricas de cimento Dissertação (Mestrado em Saúde Pública) - Faculdade de Saúde Pública da Universidade de São Paulo, São Paulo

SNIC - SINDICATO NACIONAL DA INDÚSTRIA DO CIMENTO. (2008) Relatório Anual 2008. Disponível em: <http://www.snic.org.br/pdf/ relat2008-9web.pdf>. Acesso em 21 maio 2010.

TARCKIANI, A.L.S. (2003) Fornos de cimento são bom destino final. Jornal O Estadão de 28 de agosto de 2003. Disponível em: <http:// acervo.estadao.com.br/pagina/\#!/20030828-40126-nac-1-pri-a1-not/ busca/pneu>. Acesso em 20 de maio de 2010. 